\title{
Genome-wide analysis of copper, iron and zinc transporters in the arbuscular mycorrhizal fungus Rhizophagus irregularis
}

\section{Elisabeth Tamayo, Tamara Gómez-Gallego, Concepción Azcón-Aguilar and Nuria Ferrol*}

Departamento de Microbiología del Suelo y Sistemas Simbióticos, Estación Experimental del Zaidín, Consejo Superior de Investigaciones Científicas, Granada, Spain

\section{Edited by:}

Pierre-Emmanuel Courty, University

of Basel - Botanical Institute,

Switzerland

\section{Reviewed by:}

Norbert Rolland, Centre National de la Recherche Scientifique, France

Eva Zazimalova, Institute of

Experimental Botany - Academy of

Sciences of the Czech Republic,

Czech Republic

\section{${ }^{*}$ Correspondence:}

Nuria Ferrol, Departamento de

Microbiología del Suelo y Sistemas

Simbióticos, Estación Experimental

del Zaidín, Consejo Superior

de Investigaciones Científicas,

C. Profesor Albareda 1, Granada

18008, Spain

e-mail: nuria.ferrol@eez.csic.es
Arbuscular mycorrhizal fungi (AMF), belonging to the Glomeromycota, are soil microorganisms that establish mutualistic symbioses with the majority of higher plants. The efficient uptake of low mobility mineral nutrients by the fungal symbiont and their further transfer to the plant is a major feature of this symbiosis. Besides improving plant mineral nutrition, AMF can alleviate heavy metal toxicity to their host plants and are able to tolerate high metal concentrations in the soil. Nevertheless, we are far from understanding the key molecular determinants of metal homeostasis in these organisms. To get some insights into these mechanisms, a genome-wide analysis of $\mathrm{Cu}, \mathrm{Fe}$ and $\mathrm{Zn}$ transporters was undertaken, making use of the recently published whole genome of the AMF Rhizophagus irregularis. This in silico analysis allowed identification of 30 open reading frames in the $R$. irregularis genome, which potentially encode metal transporters. Phylogenetic comparisons with the genomes of a set of reference fungi showed an expansion of some metal transporter families. Analysis of the published transcriptomic profiles of $R$. irregularis revealed that a set of genes were up-regulated in mycorrhizal roots compared to germinated spores and extraradical mycelium, which suggests that metals are important for plant colonization.

Keywords: arbuscular mycorrhizal fungi, copper, iron, metal transporters, Rhizophagus irregularis, symbiosis, zinc

\section{INTRODUCTION}

The transition metals $\mathrm{Fe}, \mathrm{Cu}$ and $\mathrm{Zn}$ play essential and catalytic roles throughout the cell in various subcellular compartments. These metal cofactors are critical for processes such as transcription, translation, the production of ATP in the mitochondria and the scavenging of toxic free radicals (van Ho et al., 2002; Schaible and Kaufmann, 2004; Kim et al., 2008). However, these metals are a highly reactive group of elements and are toxic at high concentrations (Valko et al., 2005). Therefore, their biological concentrations are finely regulated in living cells. To maintain micronutrient homeostasis, all organisms have developed a complex network of metal uptake, chelation, trafficking and storage processes (Festa and Thiele, 2011). Transporters represent the first line of defense to perturbations of cellular and subcellular metal homeostasis and constitute an important component of this network. When metal reserves are depleted, transporters contribute to the specific supply and distribution of the needed cofactor before deficiency symptoms appear. However, when the concentration of metal within the cell exceeds the cell's buffering capacity, transporters provide the route to expel excess cofactors before toxicity occurs (Nies, 2007). The toxic heavy metals, such as cadmium, lead, mercury, and nickel, have no physiological function but compete with the transporters of the essential biological metals. Therefore, the activity and specificity of the transporters of physiologically important heavy metals also control the lethality of the toxic metals.

Arbuscular mycorrhizal fungi (AMF) are soil microorganisms that establish symbiotic mutualistic associations with most land plants. These fungi provide their host plants an efficient supply of low mobility mineral nutrients, mainly phosphorus and some micronutrients such as $\mathrm{Cu}$ and $\mathrm{Zn}$. Thanks to the hyphal network they develop in the soil, AMF acquire nutrients not only for their own needs, but also for delivering them to the host plant. In return, the plant supplies the fungus with carbon compounds (Smith and Read, 2008). Besides improving plant mineral nutrition, AMF can alleviate heavy metal toxicity to their host plants (Göhre and Paszkowski, 2006; Lingua et al., 2008). Heavy metal tolerant AMF ecotypes have been isolated from polluted soils and these indigenous populations cope better with heavy metal-toxicity than those isolated from unpolluted soils (del Val et al., 1999). To persist in environments with high heavy metal content, AMF have evolved a series of strategies to avoid the damage produced by the metal, such as compartmentalization of the metal excess in some spores (González-Guerrero et al., 2008; Cornejo et al., 2013) and highly efficient homeostatic mechanisms (Ferrol et al., 2009; González-Guerrero et al., 2009). Despite the central role of metal transporters in heavy metal homeostasis, only a gene encoding a $\mathrm{Zn}$ transporter has been characterized in AMF to date (González-Guerrero et al., 2005).

With the genome of Rhizophagus irregularis available (Tisserant et al., 2013), we have the unique opportunity to identify and present a global view of proteins involved in heavy metal transport in an AM fungus. In this work we have taken advantage of the recently released genome sequence of $R$. irregularis to establish a 
repertoire of candidate genes potentially involved in the transport of $\mathrm{Cu}, \mathrm{Fe}$ and $\mathrm{Zn}$ in this fungus and to interpret them in light of its extremely adaptable character to grow in conditions of heavy metal deficiency or toxicity. This $R$. irregularis repertoire has been compared with that present in some reference fungi. To get some clues about the expression profiles of these genes throughout the fungal life cycle, we explored the published transcriptomic profiles in the extraradical mycelium (ERM) and symbiotic roots (intraradical mycelium, IRM) obtained using the R. irregularis expression oligoarray (Tisserant et al., 2012) and the RNA-Seq reads obtained from germinated spores and Medicago-colonized roots (Tisserant et al., 2013).

\section{MATERIALS AND METHODS GENE IDENTIFICATION}

Amino acid sequences of fungal $\mathrm{Cu}, \mathrm{Fe}$, and $\mathrm{Zn}$ transporters were retrieved from the freely accessible transport databases $\mathrm{TCDB}^{1}$ and TransportDB ${ }^{2}$. These sequences were used to search for orthologous sequences in the filtered model dataset of $R$. irregularis on the JGI website ${ }^{3}$ via a protein BLAST. A second search was performed via a keyword search directly.

Since many of the fungal reference proteins were phylogenetically distant from $R$. irregularis, manually curated Laccaria bicolor 4 Tuber melanosporum ${ }^{5}$ and Rhizopus oryzae ${ }^{6}$ databases were used to look for additional orthologous sequences in the filtered model dataset of $R$. irregularis. This was also done via a BLASTp, run with the standard program settings.

\section{SEQUENCES ANALYSES}

Searches for conserved domains in the orthologous proteins found in $R$. irregularis were performed using the Conserved Domain Database at $\mathrm{NCBI}^{7}$. Predictions of putative transmembrane domains were made using the TMHMM Server v.2.0 ${ }^{8}$ and SMART software ${ }^{9}$. Full-length amino acid sequences were aligned with the orthologous sequences of a number of fungi representatives of distinct taxonomic groups by CLUSTALW ${ }^{10}$. Alignments were imported into the Molecular Evolutionary Analysis (MEGA) package version 6 . Phylogenetic analyses were performed using the Neighbor-Joining (NJ) method implemented in MEGA using the Poisson correction model and pairwise deletion of gaps option for distance computation. Bootstrap analyses were carried out with 1000 replicates.

\section{RESULTS AND DISCUSSION}

The release of the $R$. irregularis genome (Tisserant et al., 2013; Lin et al., 2014) allowed making a genome-wide inventory of genes coding for $\mathrm{Cu}, \mathrm{Fe}$, and $\mathrm{Zn}$ transporters. This in silico analysis

\footnotetext{
${ }^{1}$ http://www.tcdb.org/

${ }^{2}$ http://www.membranetransport.org/

${ }^{3}$ http://genome.jgi-psf.org/Gloin 1

${ }^{4}$ http://genome.jgi-psf.org/Lacbi2

${ }^{5} \mathrm{http}: / / g e n o m e . j g i . d o e . g o v / T u b m e 1$

${ }^{6} \mathrm{http}$ //genome.jgi.doe.gov/Rhior3

${ }^{7}$ http://www.ncbi.nlm.nih.gov/cdd

${ }^{8} \mathrm{http}: / /$ www.cbs.dtu.dk/services/TMHMM/

${ }^{9}$ http://smart.embl-heidelberg.de/

${ }^{10}$ http://www.ebi.ac.uk/Tools/msa/clustalw2/
}

allowed identification of 30 open reading frames in the $R$. irregularis genome, which potentially encode heavy metal transporters. These candidate genes belong to several multigene families. Table 1 lists the eight phylogenetic families to which these proteins belong and the major heavy metal substrate for each transporter. These heavy metal transport families are described in the following sections.

\section{COPPER}

Despite the long history of $\mathrm{Cu}$ as fungicide, AMF are able to grow and persist in $\mathrm{Cu}$ contaminated soils. The morphological alterations observed in the ERM of $R$. irregularis grown in vitro in association with root organ cultures in media without $\mathrm{Cu}$ or with $\mathrm{Cu}$ concentrations that are lethal to a majority of other organisms reflect its extremely adaptable character (Figure 1). Several studies have shown that AMF finely regulate the cytosolic $\mathrm{Cu}$ levels when confronted to excess $\mathrm{Cu}$ (González-Guerrero et al., 2008) and that the fungus responds to $\mathrm{Cu}$ toxicity by inactivating the excess of $\mathrm{Cu}$ in the cytosol through the activity of metallothioneins and the activation of antioxidant defenses (for a review see Ferrol et al., 2009). However, nothing is known about the $\mathrm{Cu}$ transporters that move $\mathrm{Cu}$ across the $\mathrm{R}$. irregularis membranes. The two major families of $\mathrm{Cu}$ transporters identified in the $R$. irregularis genome are described below.

\section{The copper transporter (CTR) family}

Our in silico analysis revealed that $R$. irregularis likely acquires $\mathrm{Cu}$ through the activity of a transporter belonging to the CTR family of $\mathrm{Cu}$ transport proteins. This protein family is highly conserved across all fungal species and mediates $\mathrm{Cu}$ transport into the cytoplasm. CTR proteins are small integral membrane proteins that contain three transmembrane domains, with the $\mathrm{N}$-terminus located in the extracellular space and the C-terminus in the cytosol. A series of clustered methionine residues in the hydrophilic extracellular domain, and a MXXXM motif in the second transmembrane domain, are important for $\mathrm{Cu}$ uptake. These methionine residues probably coordinate $\mathrm{Cu}$ during the process of metal transport (Yuan et al., 2011).

In Saccharomyces cerevisiae, $\mathrm{Cu}$ is transported into the cytosol by three high-affinity transporters (CTR1, CTR2, and CTR3). While CTR1 and CTR3 are located in the plasma membrane, and acquire $\mathrm{Cu}$ from the environment (Dancis et al., 1994; Marjorette et al., 2000), CTR2 is found in the tonoplast and pumps $\mathrm{Cu}$ into the cytosol (Portnoy et al., 2001; Puig and Thiele, 2002). The $R$. irregularis genome also contains three genes putatively encoding CTRs. The predicted genes and proteins have been named according to their orthologs in S. cerevisiae. These proteins clustered into two different clades in a phylogenetic NeighborJoining tree. RiCTR1 and RiCTR3 are more closely related to the $S$. cerevisiae plasma membrane CTR proteins, while RiCTR2 is highly homologous to the fungal vacuolar CTR2 transporters (Figure 2).

Since CTR proteins are highly specific for reduced $\mathrm{Cu}^{+}$and $\mathrm{Cu}$ widely exists as $\mathrm{Cu}^{2+}$, transport by CTR is dependent on reduction of $\mathrm{Cu}$ by a ferric/cupric reductase (Hassett and Kosman, 1995). Orthologous sequences of the fungal cell surface $\mathrm{Cu}$ metalloreductases encoded by the FRE genes are present in the R. irregularis 
Table 1 | Overview of the putative metal transporters identified in the Rhizophagus irregularis genome.

\begin{tabular}{lllll}
\hline Protein name & JGI ID & $\begin{array}{l}\text { Major } \\
\text { substrate }\end{array}$ & $\begin{array}{l}\text { Ratio } \\
\text { IRM/spore }\end{array}$ & $\begin{array}{l}\text { Ratio } \\
\text { IRM/ERM }\end{array}$ \\
\hline CTR family & & & & \\
CTR1 & 153709 & $\mathrm{Cu}$ & 0.5 & - \\
CTR2 & 335281 & $\mathrm{Cu}$ & 5 & 2.9 \\
CTR3 & 67076 & $\mathrm{Cu}$ & 0.3 & -
\end{tabular}

$\begin{array}{lllll}\mathbf{P}_{\mathbf{1 B}} \text {-ATPase family } & & & \\ \text { CCC2.1 } & 335789 & \mathrm{Cu} & 2.6 & 2.6 \\ \text { CCC2.2 } & 83433 & \mathrm{Cu} & 1 & - \\ \text { CCC2.3 } & 236684 & \mathrm{Cu} & 0.7 & - \\ \text { CRD1 } & 32309 & \mathrm{Cu} & 1 & - \\ \text { SIT family } & & & & \\ \text { SIT1 } & 305535 & \text { Sid.-Fe } & 0.6 & - \\ \text { SIT2 } & 193231 & \text { Sid.-Fe } & 1.9 & 1.9 \\ \text { SIT3 } & 71812 & \text { Sid.-Fe } & 1 & -\end{array}$

$\begin{array}{lllll}\text { OFet family } & & & & \\ \text { FTR1 } & 347887 & \mathrm{Fe} & 10 & -\end{array}$

$\begin{array}{lllll}\text { FTR2 } & 34848 & \mathrm{Fe} & 1.5 & - \\ \text { VIT family } & & & & \\ \text { CCC1.1 } & 278480 & \mathrm{Fe} / \mathrm{Mn} & 0.9 & 3.4 \\ \text { CCC1.2 } & 57183 & \mathrm{Fe} / \mathrm{Mn} & 0.04 & 0.1 \\ \text { CCC1.3 } & 340222 & \mathrm{Fe} / \mathrm{Mn} & 2.7 & -\end{array}$

\begin{tabular}{lllll} 
ZIP family & & & \\
ZRT1 & 327155 & $\mathrm{Zn}$ & 420 & 8 \\
YKE4 & 337446 & $\mathrm{Zn}$ & 0.9 & - \\
ATX2 & 80864 & $\mathrm{Mn}$ & 1.2 & - \\
ZRT3.1 & 13899 & $\mathrm{Zn}$ & 3.5 & - \\
ZRT3.2 & 336612 & $\mathrm{Zn}$ & 3 & 14 \\
CDF family & & & & \\
ZnT1 & 70407 & $\mathrm{Zn}$ & 100 & - \\
ZnT2 & 286233 & $\mathrm{Zn}$ & 1 & - \\
MMT1 & 85722 & $\mathrm{Fe}$ & 2 & - \\
MSC2 & 340453 & $\mathrm{Zn}$ & 0.9 & 0.9 \\
ZRG17 & 67256 & $\mathrm{Zn}$ & 1 & 0.9 \\
MnT1 & 232215 & $\mathrm{Mn}$ & 0.8 & 0.8 \\
NRAMP family & & & & \\
SMF1 & 136431 & $\mathrm{Mn} / \mathrm{Fe}$ & 3 & 0.9 \\
SMF2 & 89717 & $\mathrm{Mn}$ & 6 & - \\
SMF3.1 & 313253 & $\mathrm{Fe}$ & 1.9 & - \\
SMF3.2 & 337501 & $\mathrm{Fe}$ & 0.7 & 1 \\
\hline
\end{tabular}

Columns 1-5 contain protein name, protein JGI identification (JGI ID) number, predicted major metal transported, ratio of expression levels in $M$. truncatula symbiotic roots (IRM) to 2 d germinated spores (calculated from the RNA-seq reads in Tisserant etal., 2013), and ratio of expression levels in IRM to ERM (from Tisserant etal., 2012). CTR, Cu transporter; SIT, siderophore-iron (Sid.-Fe) transporter; OFet, oxidase-dependent $\mathrm{Fe}^{2+}$ transporter; VIT, vacuolar iron transporter; ZIP, zinc-iron permease; CDF, cation diffusion facilitator; NRAMP, natural resistance-associated macrophage protein. genome (see next section), suggesting that the $\mathrm{Cu}$ reduction process is similar to that described for other fungi. Upon entering the cytoplasm, small molecules and proteins sequester the $\mathrm{Cu}$ ions, and the resulting concentration gradient drives transport by CTR.

Inspection of the available gene expression profiles of R. irregularis revealed that RiCTR2 is up-regulated in Medicago truncatula colonized roots, suggesting that some $\mathrm{Cu}$ is mobilized from the internal stores in the IRM probably to provide $\mathrm{Cu}$ to $\mathrm{Cu}$-binding proteins that might be required for fungal colonization (Table 1).

\section{Copper-transporting P-type ATPases}

Copper-transporting ATPases belong to the heavy metal P-type ATPase family (HMA), also known as $\mathrm{P}_{1 \mathrm{~B}}$-ATPases, which couples ATP hydrolysis to the efflux of positively charged metals from the cytoplasm. These proteins possess eight transmembrane domains, a large cytoplasmic loop, including ATP-binding and phosphorylation sites, and at least one conserved CPX motif (i.e., CPC) believed to be involved in metal cation translocation across the membrane.

Four candidate genes putatively encoding $\mathrm{Cu}^{+}$-ATPases have been found in the $R$. irregularis genome, which represents an expansion compared with other fungi (Tables 1 and 2). These genes were clustered in two different groups in a phylogenetic tree (Figure 3). Three of them were grouped in a clade comprising the well characterized ortholog of S. cerevisiae CCC2, a protein that receives $\mathrm{Cu}$ from the $\mathrm{Cu}$ chaperone ATX1 via a direct protein-protein interaction, and pumps $\mathrm{Cu}$ into the lateor post-Golgi compartment to load $\mathrm{Cu}$ into a multicopper oxidase required for Fe uptake (see next section) and, presumably, to other Cu-dependent proteins (Yuan et al., 1995). The other paralog, RiCRD1, groups in a different clade comprising various orthologs of CRD1, a plasma membrane $\mathrm{Cu}^{+}$-ATPase that plays a major role in $\mathrm{Cu}$ detoxification via $\mathrm{Cu}$ efflux in the opportunistic fungus Candida albicans (Weissman et al., 2000). Although it has been suggested that functions of the fungal $\mathrm{Cu}$-ATPases can be inferred from their positions in a phylogenetic tree (Saitoh et al., 2009), a detailed characterization of the $R$. irregularis paralogs is needed to understand their physiological functions.

Analysis of the available expression profiles of $R$. irregularis revealed a 2.6-fold up-regulation of RiCCC2.1 gene expression in mycorrhizal roots relative to the expression levels in spores and ERM. No data are still available of the expression profiles of the other paralogs in the ERM. Up-regulation of RiCCC2.1 in the symbiotic stage, as it has been observed for the Cu transporter RiCTR2, suggests a role for these proteins to supply $\mathrm{Cu}$ to other enzymes required for fungal accomodation or functioning in the root tissues. In this respect, it has been shown that the CTR2 ortholog of the plant pathogen Colletotrichum gloeosporioides (Barhoom et al., 2008) and the CCC2 orthologs of Colletotrichum lindemuthianum (Parisot et al., 2002) and Botrytis cinerea (Saitoh et al., 2010) are required for pathogenicity.

\section{IRON \\ Iron uptake}

Although Fe is abundant in nature, this metal has a low availability because it is most commonly found as ferric hydroxide, which is 

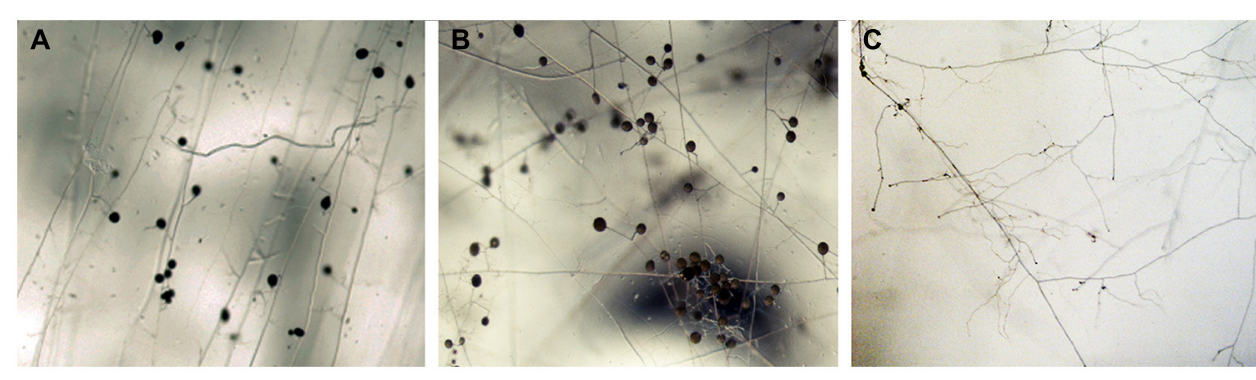

FIGURE 1 | Effect of Cu on extraradical hyphal development of Rhizophagus irregularis grown in vitro in association with root organ cultures. Extraradical mycelium (ERM) was grown in minimal medium lacking
Cu (A), containing $0.5 \mu \mathrm{M} \mathrm{Cu}$ (B), or $500 \mu \mathrm{M} \mathrm{Cu}$ (C). Mycelial architecture was altered markedly when the fungus developed in a $\mathrm{Cu}$-free media (A) and in the presence of $500 \mu \mathrm{M} \mathrm{Cu}$ (C). a rather stable and poorly soluble compound. A common strategy engaged by fungi to efficiently get the metal involves "sequestering" of Fe through the production and subsequent uptake of siderophores, which are small molecules that act as high-affinity Fe chelators (Haas et al., 2008). Another important Fe uptake mechanism involves a group of specialized membrane proteins that are part of the reductive iron assimilation system (RIA). In this highaffinity uptake machinery, the metal is reduced from $\mathrm{Fe}^{3+}$ to $\mathrm{Fe}^{2+}$ (in order to increase Fe solubility) by membrane-bound ferrireductases, and then it is rapidly internalized by the concerted action of a ferroxidase and a permease that form a plasma membrane protein complex (Kosman, 2010).

A number of fungi harbor both types of high affinity systems, examples are Ustilago maydis, Schizosaccharomyces pombe,
Aspergillus fumigatus and Fusarium graminearum (Mei et al., 1993; Roman et al., 1993; Askwith and Kaplan, 1997; Schrettl et al., 2004; Eichhorn et al., 2006; Schwecke et al., 2006; Greenshields et al., 2007). Others, such as S. cerevisiae, C. albicans and Cryptococcus neoformans (Schwyn and Neilands, 1987; Lesuisse and Labbe, 1989; Howard, 1999), are unable to synthesize siderophores but can utilize those produced by other organisms.

\section{The siderophore pathway}

Arbuscular mycorrhizal fungi are assumed to play a key role in Fe uptake and delivery to their associated host plants. However, it is still unknown whether AMF produce siderophores. The majority of fungal siderophores are hydroxamates. The first committed step in the biosynthesis of fungal hydroxamate

Table 2 | Number and classification of the putative $\mathrm{Cu}, \mathrm{Fe}$, and $\mathrm{Zn}$ transporters identified in the genome of $R$. irregularis and in the genomes of the reference fungi used in this study.

\begin{tabular}{|c|c|c|c|c|c|c|c|c|c|c|c|c|c|c|}
\hline & \multicolumn{7}{|c|}{ Basidiomycota } & \multicolumn{5}{|c|}{ Ascomycota } & \multirow[b]{2}{*}{ 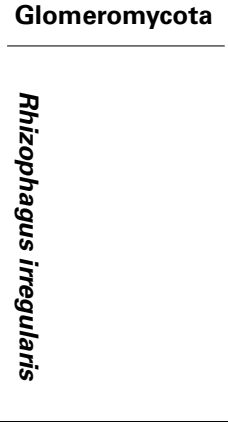 } & \multirow{2}{*}{ 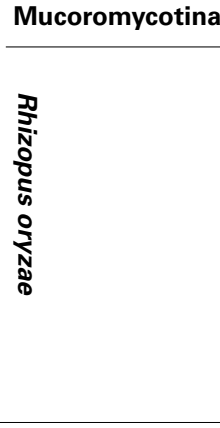 } \\
\hline & 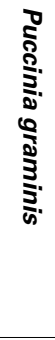 & 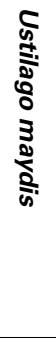 & 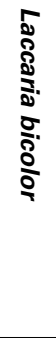 & 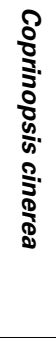 & 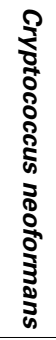 & 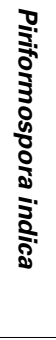 & 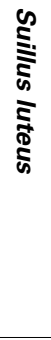 & 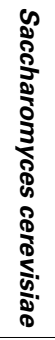 & 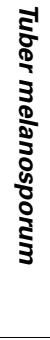 & 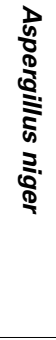 & 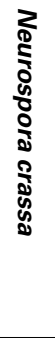 & 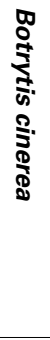 & & \\
\hline OFet (Ftr1) & 1 & 1 & 3 & 0 & 3 & 1 & 1 & 2 & 1 & 3 & 1 & 1 & 2 & 1 \\
\hline Low affinity $\mathrm{Fe}^{2+}$ transporter & 0 & 0 & 0 & 0 & 0 & 0 & 0 & 1 & 0 & 1 & 0 & 1 & 0 & 0 \\
\hline CTR & 2 & 1 & 2 & 4 & 2 & 3 & 3 & 3 & 2 & 4 & 4 & 3 & 3 & 3 \\
\hline$P_{1 B}$-type ATPases & 1 & 2 & 2 & 1 & 1 & 2 & 3 & 1 & 3 & 2 & 2 & 2 & 4 & 3 \\
\hline CDF & 2 & 5 & 9 & 5 & 5 & 5 & 7 & 6 & 4 & 6 & 5 & 6 & 6 & 4 \\
\hline
\end{tabular}

CTR, Cu transporter; OFet, oxidase-dependent Fe ${ }^{2+}$ transporter; VIT, vacuolar iron transporter; ZIP, zinc-iron permease; CDF, cation diffusion facilitator; NRAMP, natural resistance-associated macrophage protein. 


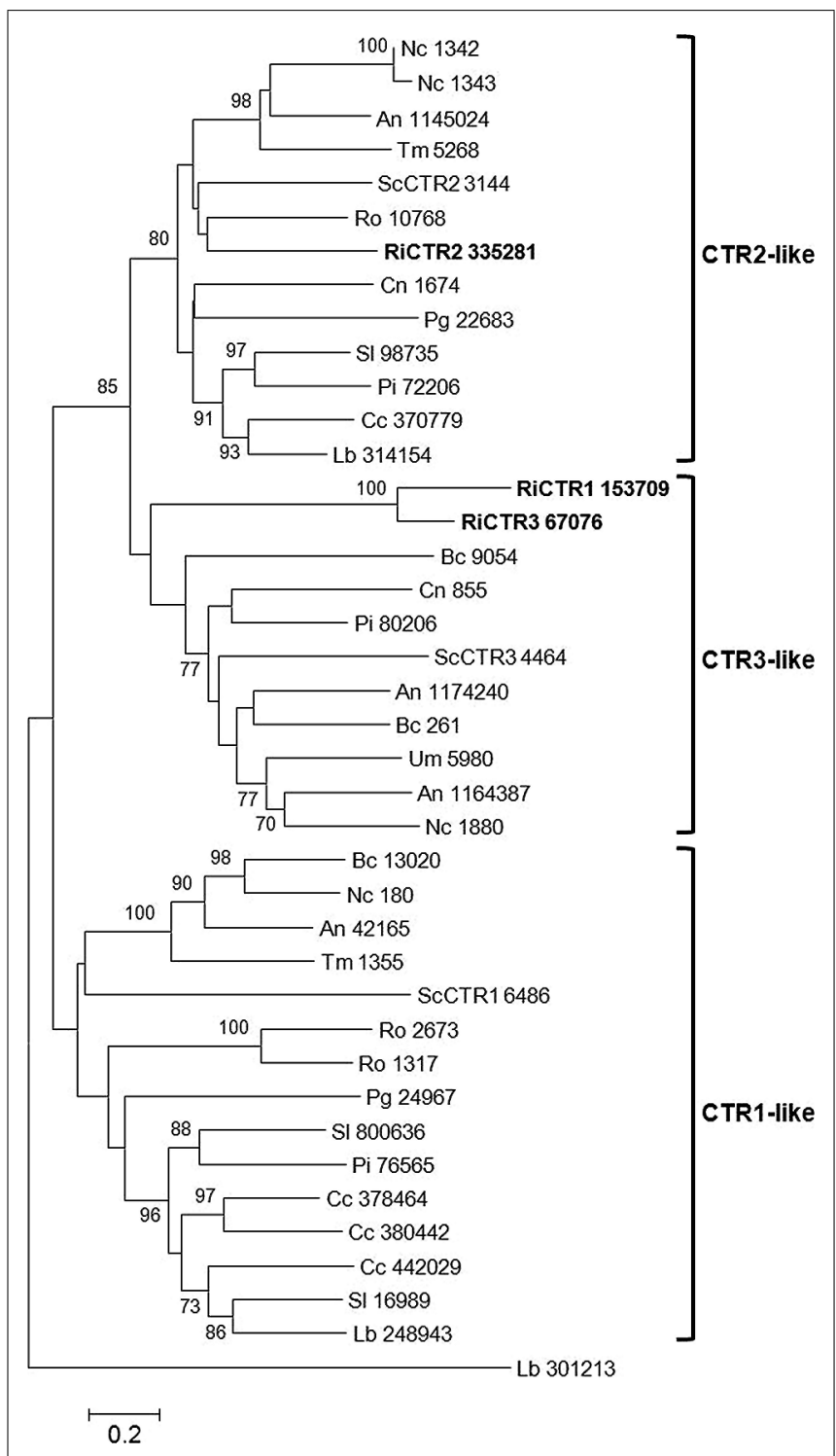

FIGURE 2 | Phylogenetic relationships of the Rhizophagus irregularis copper transporters (CTR) with homologous sequences from selected species representative of the major fungal phyla. The Neighbor-Joining tree was created with MEGA 6. Protein JGI identification numbers are indicated. R. irregularis genes are shown in bold. Organisms: An, Aspergillus niger; Bc, Botrytis cinerea; Cc, Coprinopsis cinerea; $\mathrm{Cn}$, Cryptococcus neoformans; Lb, Laccaria bicolor; Nc, Neurospora crassa; Pi, Piriformospora indica; Pg, Puccinia graminis; Sc, Saccharomyces cerevisiae; SI, Suillus luteus; Tb, Tuber melanosporum; Ri, Rhizophagus irregularis; Ro, Rhizopus oryzae; Um, Ustilago maydis. Bootstrap values above 70 and supporting a node used to define a cluster are indicated.

siderophores is the N5-hydroxylation of ornithine catalyzed by ornithine-N5-monooxygenase (named Sid1/SidA). The absence of a Sid1/SidA ortholog in a fungal genome is generally taken as a strong evidence of no siderophore production. Inspection of the $R$. irregularis genome indicates that it does not contain Sid1/SidA orthologs. Similarly, the genomes of Saccharomycotina and Mucoromycotina and some Basidiomycota lack genes coding for this enzyme, which is in agreement with the observed lack of siderophore production by these fungi (Lesuisse and Labbe, 1989; Plattner and Diekmann, 1994). Interestingly, although the L. bicolor genome also lacks Sid1/SidA orthologous genes, production of a set of different hydroxamate siderophores by L. bicolor has been recently reported (Haselwandter et al., 2013).

A gene encoding a putative bifunctional iucA/iucC siderophore biosynthetic protein (RiSid1) that is highly expressed in mycorrhizal roots was found in the genome of $R$. irregularis. IucA and iucC catalyse discrete steps in the biosynthesis of the siderophore aerobactin from $\mathrm{N}$ epsilon-acetyl- $\mathrm{N}$ epsilon-hydroxylysine and citrate. The C-terminal region of RiSid1 is related to the bacterial ferric iron reductase FhuF-like transporter. The genomes of the reference fungi used in this study also contain orthologs of this gene. Therefore, the production of siderophores by $R$. irregularis remains uncertain.

Irrespective of their ability to produce siderophores, fungi have siderophore transporters that allow them to uptake different types of these small chelators, including bacterial ones like coprogen or enterobactin. This allows several fungi to take advantage of the siderophores produced by other organisms, securing in such manner their own iron needs (Haas et al., 2008; Saha et al., 2013). This type of siderophore transporters belong to the SIT (siderophore-iron transporter) subfamily (2.A.1.16) of the major facilitator superfamily, a protein subfamily present exclusively in fungi (and not in other eukaryotes or prokaryotes). SITs are secondary transporters with 12-14 predicted transmembrane domains, which likely function as proton symporters energized by the plasma membrane potential (Haas et al., 2003; Philpott and Protchenko, 2008). Searches in the R. irregularis genome using as query the SIT genes of S. cerevisiae and S. pombe allowed identification of three putative siderophore transporters (RiSIT1, RiSIT2, and RirSIT3), which are expressed in all fungal structures (Table 1). Detailed characterization of these transporters is needed to determine their substrate specificity.

\section{The reductive iron assimilation (RIA) pathway}

The reductive iron assimilation pathway starts with reduction of ferric iron sources to the more soluble ferrous iron $\mathrm{Fe}^{2+}$ by plasma membrane-localized ferrireductases. $R$. irregularis contains a putative ferrireductase (RiFRE1) that displays the highest homology to the S. cerevisiae FRE2 (23\% identity and $43 \%$ similarity), a protein that can reduce oxidized forms of both $\mathrm{Fe}$ and $\mathrm{Cu}$. RiFRE1 encodes a 541 amino acids protein that has seven transmembrane regions, several $\mathrm{NAD}(\mathrm{P}) \mathrm{H}$ binding motifs and a FAD binding motif.

Reduced Fe is then specifically taken up by a high-affinity transport complex consisting of a ferroxidase and a Fe permease, the oxidase-dependent $\mathrm{Fe}^{2+}$ transporter (OFeT), or non-specifically through other plasma membrane divalent cation transporters, as it will be discussed below. In S. cerevisiae, $\mathrm{Fe}^{2+}$ can be also taken up by the low-affinity Fe transporter Fet4 (Dix etal., 1994). This low-affinity system seems to be absent in $R$. irregularis as well as in the other reference fungi used in this study, except the ascomycetes $S$. cerevisiae, A. niger, and B. cinerea (Table 2). 


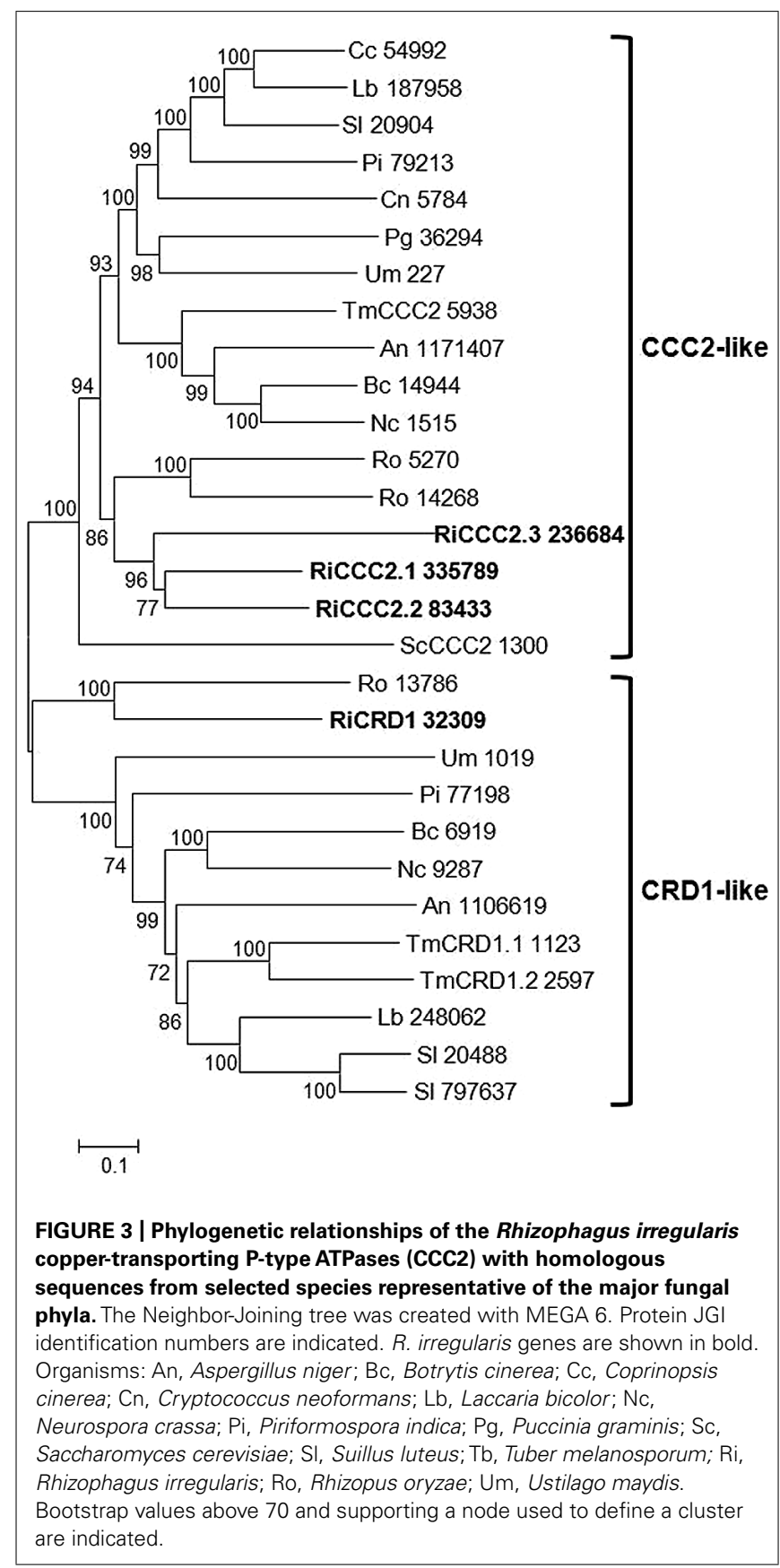

\section{The oxidase-dependent $\mathrm{Fe}^{2+}$ transporter (OFeT) family}

In S. cerevisiae, the ferroxidation/permeation pathway is mediated by the ferroxidase FET3 and the iron permease FTR1. This bipartite complex operates with an apparent $K m$ of $0.2 \mu \mathrm{M}$. The $\mathrm{Fe}^{2+}$ to be transported is first oxidized by FET3, and then transported into the cytosol as $\mathrm{Fe}^{3+}$ by FTR1 via a channeling mechanism (Kwok et al., 2006). The advantage gained by redox coupling of this transport mechanism is unclear, although it possibly imparts specificity to transport. FET3 contains a single transmembrane domain and an extracellular multicopper oxidase domain, showing remarkable similarity to other multicopper oxidases, such as laccases and ascorbate oxidases. Searches in the $R$. irregularis genome for ferroxidases retrieved several genes putatively encoding multicopper oxidases (data not shown). The encoded proteins are more closely related to members of the ferroxidase/laccase subfamily of multicopper oxidases than to ferroxidases sensu stricto. Detailed characterization of these genes will enable identification of the FET3 ortholog.

Two putative orthologs of yeast FTR1, named RiFTR1 and RiFTR2, have been found in the R. irregularis genome. RiFTR1 and RiFTR2 were more similar to the FTR1 homolog of the Bryophyte Physcomitrella patens (43\% identity, 66\% similarity, and 37\% identity, $60 \%$ similarity, respectively) than to fungal FTRs. Phylogenetic analyses of the FTR protein sequences of the reference fungi used in this study revealed that RiFTR1 and RiFTR2 clustered together and separated from the other sequences (Figure 4). The two $R$. irregularis Fe permeases were predicted to have seven transmembrane helixes and the two REXXE motifs typical of Fe transporters.

Many fungal species, such as S. cerevisiae, C. albicans, $F$. graminearum, and C. neoformans (Urbanowski and Piper, 1999;

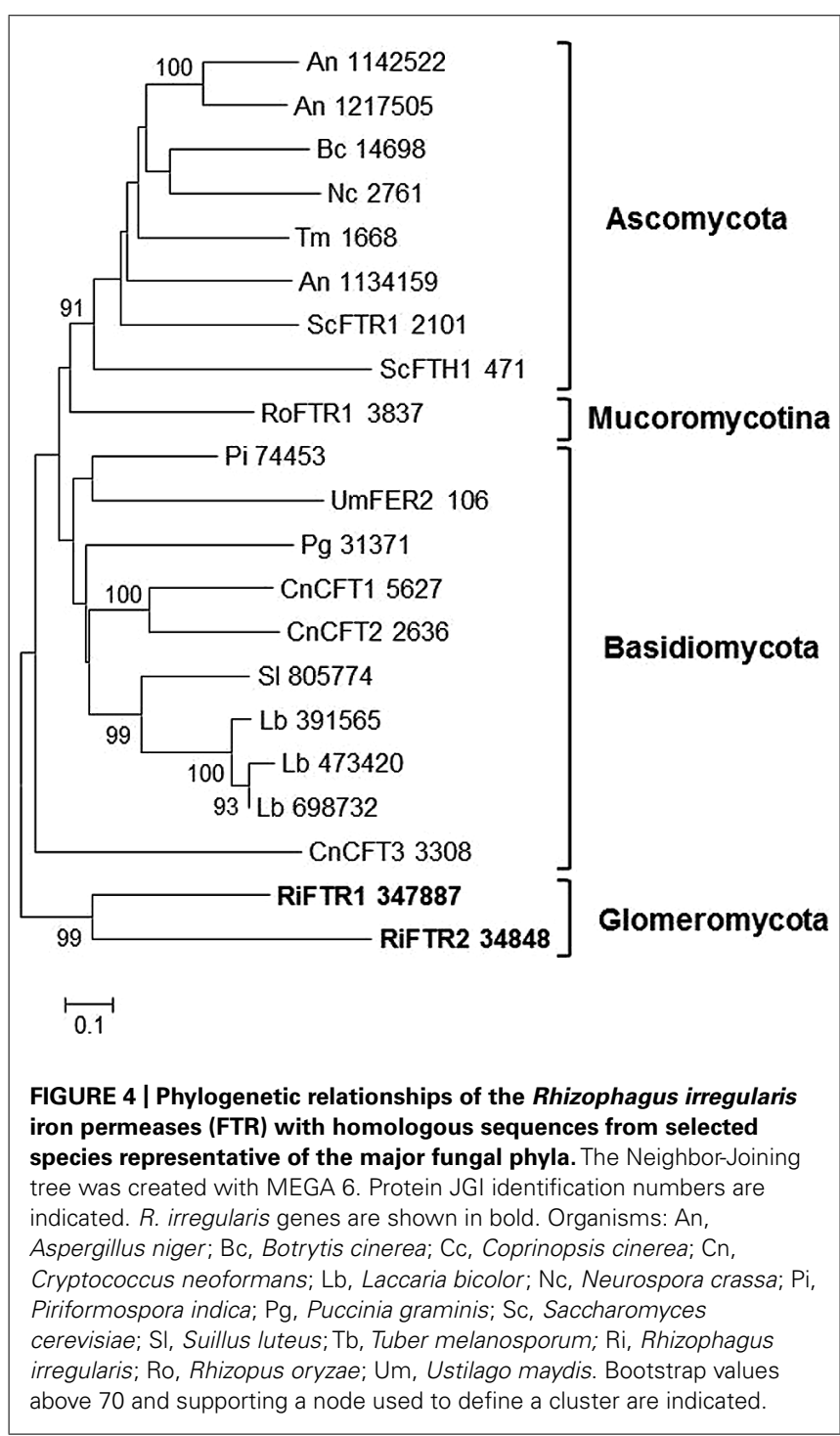


Fang and Wang, 2002; Park et al., 2006; Han et al., 2012), also possess two or more FTR paralogs. In S. cerevisiae, ScFTH1 is located in the vacuole and together with the ferroxidase FET5 exports Fe from the vacuole into the cytosol (Spizzo et al., 1997; Urbanowski and Piper, 1999). However, in C. neoformans, which possesses three FTRs, two of them are redundant (Han etal., 2012). Functional characterization of RiFTR1 and RiFTR2 is needed to determine if one of these Fe permeases is involved in Fe mobilization of vacuolar stores or if they are functionally redundant.

Expression analysis of the genes putatively involved in the ferroxidation/permeation pathway in the available transcriptomic data of $R$. irregularis revealed that the two Fe permeases identified in the genome are expressed in germinated spores and mycorrhizal roots (Table 1) and that some of the putative multicopper oxidases are expressed in all fungal structures (data not shown), which suggest that the Fe reductive assimilation pathway operates in AM fungi. Interestingly, the Fe permease RiFTR1 was up-regulated (10-fold) during the symbiotic phase of the fungus (Table 1). These data suggest that this high-affinity Fe uptake system plays a role not only in Fe uptake from the soil, but also during the biotrophic phase of the fungus. In this respect, it is noteworthy that full virulence of the plant pathogenic fungus $U$. maydis requires a ferroxidation/permeation Fe uptake system (Eichhorn et al., 2006) and it has been postulated that Fe acquisition through the siderophore-mediated pathway is necessary for Epichloë festucae to maintain mutualism with perennial ryegrass (Johnson et al., 2013).

The significance of the expression profiles of the Fe uptake systems present in $R$. irregularis is unknown. A recent genomewide analysis of transcription patterns in defined cell-types of $M$. truncatula roots colonized by $R$. irregularis identified two metal transporters, MtNRAMP1 and MtNRAMP3 likely playing a role in Fe homeostasis, that were induced more than threefold in cortical root cells colonized by arbuscules (Hogekamp and Küster, 2013). Given that in the symbiotic interface enough Fe must be supplied for the metabolism of the plant and the fungus and that excess Fe must be avoided to prevent formation of reactive oxygen species, it is tempting to speculate that maintenance of Fe homeostasis in the symbiotic interface may be essential for the maintenance of a successful symbiosis.

\section{Vacuolar iron transport}

Several studies have highlighted the importance of the AM fungal vacuoles for storage and detoxification of heavy metals (Turnau etal., 1993; González-Guerrero et al., 2007; Nayuki et al., 2014). Iron is likely stored in the fungal vacuoles in the ferric form as polyphosphate. In yeast, $\mathrm{Fe}$ is loaded into the vacuole by CCC1, a member of the vacuolar iron transporter (VIT) family (Li et al., 2001). Homologs are found in eukaryotes, bacteria, and archaea. Most fungal species encode one CCC1 protein and some others, such as Aspergillus and Rhizopus species, encode two paralogs (Gsaller et al., 2012). In contrast, three putative paralogs have been found in R. irregularis, named RiCCC1.1, RiCCC1.2, and RiCCC1.3. As shown in the phylogenetic tree of fungal VITs, the three putative $R$. irregularis paralogs are closely related and cluster together with the $R$. oryzae homologs, clearly separated from sequences of Ascomycota and Basidiomycota (Figure 5). The three paralogs were differentially expressed in the different fungal structures. RiCCC1.1 was the most highly expressed paralog in the ERM. While RiCCC1.2 was down-regulated in mycorrhizal roots, RiCCC1.3 was up-regulated (Table 1).

When Fe is low, mobilization of the vacuolar Fe stores should be mediated by a Fe permease/oxidase complex, as it was discussed in the former section, and/or by a homolog of the $S$. cerevisiae NRAMP family member SMF3 that exports Fe from the vacuole into the cytosol (see the NRAMP family section).

\section{ZINC}

In eukaryotes, $\mathrm{Zn}$ homeostasis is largely attributed to the coordinated action of two transporter families: the ZIP (zinc-iron permease or ZRT-IRT-like Protein) and the CDF (Cation Diffusion Facilitator) families (Eide, 2006). Only three $\mathrm{Zn}$ transporters of the CDF family have been characterized so far in mycorrhizal fungi. The first one was identified in $R$. irregularis

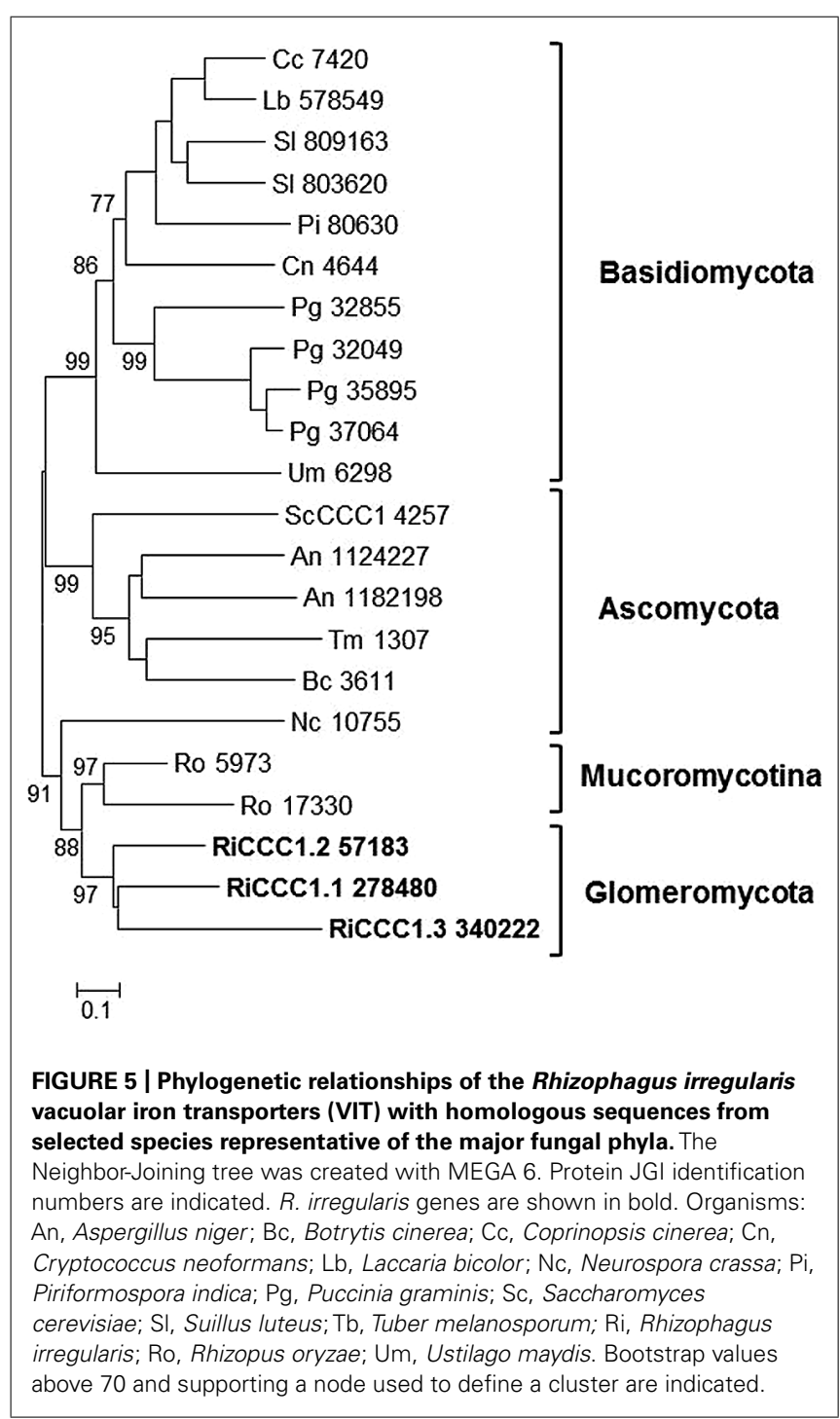




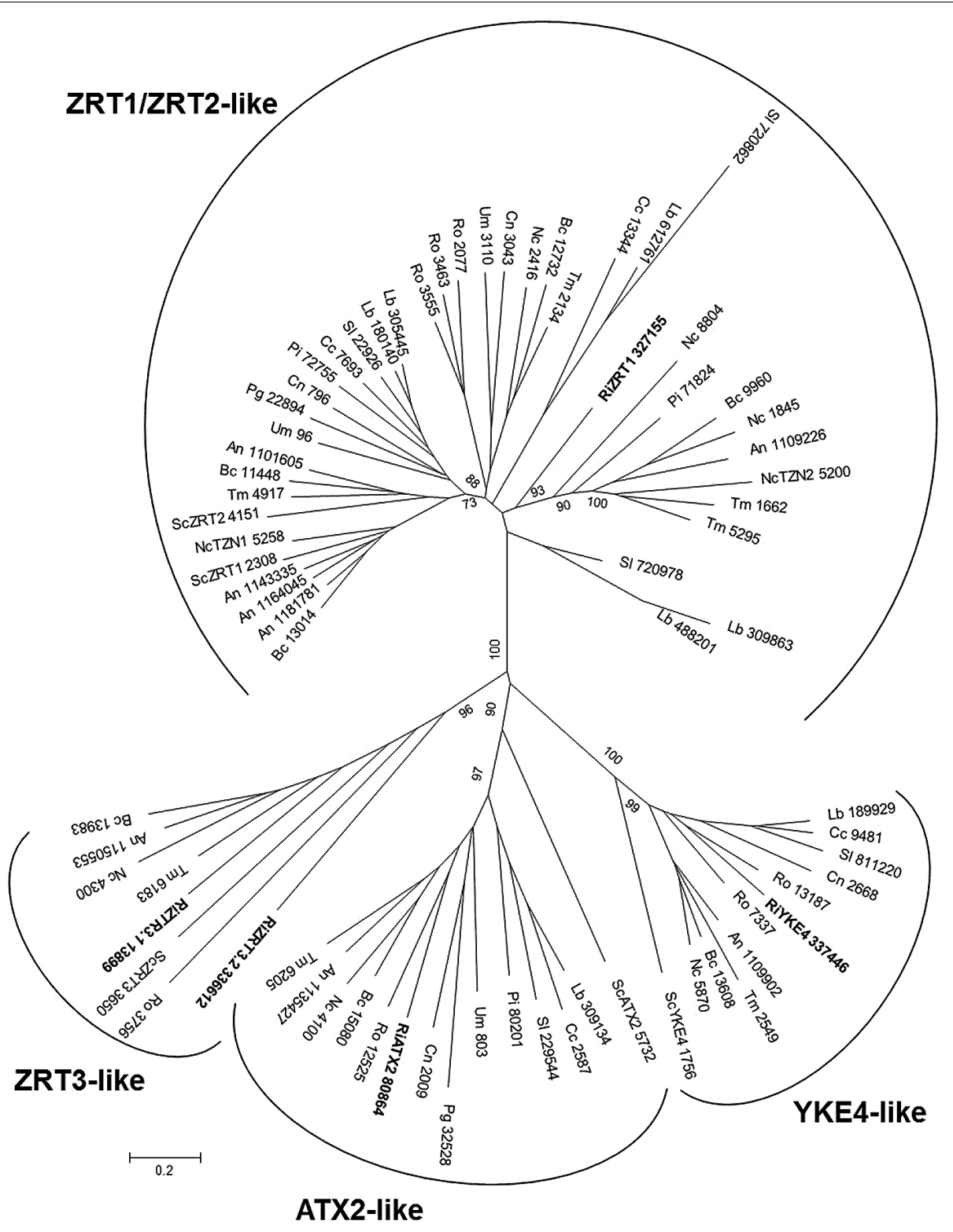

FIGURE 6 | Phylogenetic relationships of the Rhizophagus irregularis zinc-iron permeases (ZIPs) with homologous sequences from selected species representative of the major fungal phyla. The Neighbor-Joining tree was created with MEGA 6. Protein JGI identification numbers are indicated. $R$. irregularis genes are shown in bold. Organisms: An, Aspergillus niger; Bc, Botrytis cinerea; Cc,
Coprinopsis cinerea; Cn, Cryptococcus neoformans; Lb, Laccaria bicolor; Nc, Neurospora crassa; Pi, Piriformospora indica; Pg, Puccinia graminis; Sc, Saccharomyces cerevisiae; SI, Suillus luteus; Tb, Tuber melanosporum; Ri, Rhizophagus irregularis; Ro, Rhizopus oryzae; Um, Ustilago maydis. Bootstrap values above 70 and supporting a node used to define a cluster are indicated.
(González-Guerrero et al., 2005), the second in Hebeloma cylindrosporum (Blaudez and Chalot, 2011) and more recently a new one has been reported in the ericoid fungus Oidiodendron maius (Khouja et al., 2013).

\section{The zinc-iron permease (ZIP) family}

The name of the ZIP family refers to the first members that were functionally characterized, the $S$. cerevisiae Zn transporter ZRT1 and the Arabidopsis thaliana Fe transporter IRT1. A key feature of the ZIP family is that, without any yet known exceptions, these proteins transport $\mathrm{Zn}$ and/or other metal ion substrates from the extracellular space or organellar lumen into the cytoplasm. ZIP transporters are found at all phylogenetic levels including bacteria, fungi, plants, and mammals (Eide, 2006). Most ZIP proteins have eight predicted transmembrane domains and similar predicted topologies with the $\mathrm{N}$ - and C-termini of the protein located on the extracytoplasmic face of the membrane. A histidine-rich region present between transmembrane regions three and four is necessary for $\mathrm{Zn}$ selectivity (Nishida et al., 2008). 


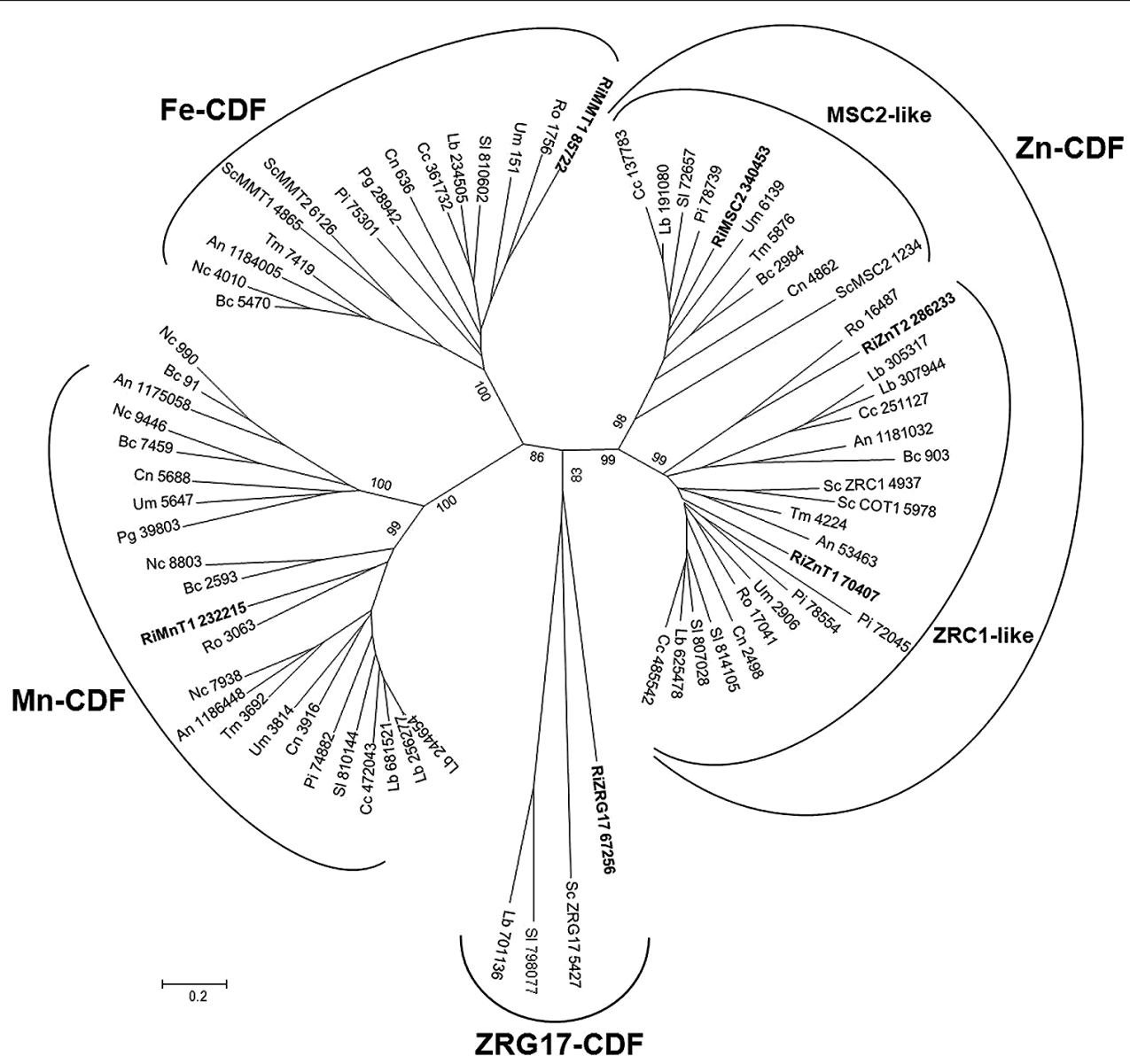

FIGURE 7 | Phylogenetic relationships of the Rhizophagus irregularis cation diffusion facilitators (CDFs) with homologous sequences from selected species representative of the major fungal phyla. The Neighbor-Joining tree was created with MEGA 6. Protein JGI identification numbers are indicated. $R$. irregularis genes are shown in bold. Organisms: An, Aspergillus niger; Bc, Botrytis cinerea; Cc,
Coprinopsis cinerea; Cn, Cryptococcus neoformans; Lb, Laccaria bicolor; Nc, Neurospora crassa; Pi, Piriformospora indica; Pg, Puccinia graminis; Sc, Saccharomyces cerevisiae; SI, Suillus luteus; Tb, Tuber melanosporum; Ri, Rhizophagus irregularis; Ro, Rhizopus oryzae; Um, Ustilago maydis. Bootstrap values above 70 and supporting a node used to define a cluster are indicated.
The number of ZIP genes in the genomes of the reference fungi ranges from two to eight (Table 2). In S. cerevisiae, five ZIP family members have been described: ZRT1, ZRT2, ZRT3, ATX2, and YKE4. The R. irregularis ZIP family also includes five candidate genes, which have been named according to their closest yeast orthologs. The fungal ZIP family is divided into four distinct subfamilies. One of the $R$. irregularis paralogs clusters with the plasma membrane high- and low-affinity Zn transporters ZRT1 and ZRT2 of S. cerevisiae in the ZRT1/ZRT2-like group (Zhao and Eide, 1996). Two paralogs were grouped in the ZRT3-like cluster and are closely related to the S. cerevisiae ZRT3, which mediates $\mathrm{Zn}$ release from the vacuole to the cytosol (Simm et al., 2007). The ATX2-like and YKE-like subfamilies including, respectively, the yeast ATX2 protein involved in Mn trafficking (Lin and Culotta, 1996) and the bidirectional Zn transporter YKE4 (Kumánovics et al., 2006), also comprised one R. irregularis gene each (Figure 6). ZIP member distribution in the phylogenetic tree was not related to organism taxonomy, but rather to substrate specificity or subcellular location suggesting ancient duplication events followed by subfunctionalization in a common ancestor.

Expression analyses revealed that all the $R$. irregularis paralogs were expressed in all the fungal structures tested. RiZRT1 was highly up-regulated in mycorrhizal roots relative to the expression levels detected in germinated spores (420-fold) and in the ERM (eightfold). The two homologs of the yeast vacuolar $\mathrm{Zn}$ transporter, RiZTR3.1 and RiZTR3.2, were also up-regulated (threefold) in mycorrhizal roots (Table 1). These expression data suggest that the fungus takes up $\mathrm{Zn}$ from the apoplast of the symbiotic interface and that a mobilization of the vacuolar $\mathrm{Zn}$ stores occurs in the IRM. These data reinforce our hypothesis that AMF must maintain proper metal homeostasis for colonization and survival in the host roots.

\section{The cation diffusion facilitator (CDF) family}

The key feature of this family is that they transport $\mathrm{Zn}$ and/or other metal ions from the cytoplasm into the lumen of intracellular organelles or to the outside of the cell. Thus, CDF proteins 
work in opposition to the ZIP transporters. CDF transporters are also found at all phylogenetic levels. Most members of this family have six predicted transmembrane domains with the $\mathrm{N}$ - and C-termini predicted to be cytoplasmic. A notable exception to this rule is the yeast MSC2 protein that forms a heteromeric CDF complex with ZRG17 to transport Zn into compartments of the secretory pathway. Like the ZIP proteins, many CDF family members have histidine rich motifs, in this case usually in the cytoplasmic loop between transmembrane domains 4 and 5. The majority of CDF family members are classified into three groups, each containing characterized members that share the same specificity toward the principally transported metal, $\mathrm{Zn}, \mathrm{Fe} / \mathrm{Zn}$, or $\mathrm{Mn}$. An additional group is the ZRG17-like subfamily, which is very distant from the $\mathrm{Zn}$-CDF but with similar biochemical characteristics (Montanini et al., 2007). Six genes putatively encoding CDFs were identified in $R$. irregularis, which have been named according to their closest yeast orthologs. Three were included in the Zn-CDF subfamily, two in the ZRC1-like cluster and one in the MSC2-like cluster (Figure 7). The ZRC1-like cluster comprises the yeast vacuolar $\mathrm{Zn}$ transporters ZRC1 and COT1 (MacDiarmid etal., 2002) and the R. irregularis CDF GiZnT1 (González-Guerrero et al., 2005, renamed here as RiZnT1). These transporters mediate $\mathrm{Zn}$ uptake into the vacuole and are involved in $\mathrm{Zn}$ tolerance. Members of the MSC2-cluster also transport $\mathrm{Zn}$, but into the endoplasmic reticulum. Another $R$. irregularis CDF, named RiMMT1, was grouped together with the S. cerevisiae mitochondrial Fe transporters MMT1 and MMT2 in the Fe-CDF subfamily and it is likely to mediate the transport of Fe. The other two homologs found, RiMnT1, and RiZRG17, were grouped in the Mn-CDF and ZRG17-like subfamilies, respectively, and are proposed to be involved in the transport of $\mathrm{Mn}$ and Zn (Montanini et al., 2007; Diss et al., 2011). Although the metal specificity of the newly identified CDF transporters of $R$. irregularis has been inferred from their distribution in the phylogenetic tree, an exhaustive functional characterization of these transporters is needed to confirm the transport processes mediated by the different isoforms.

Expression analyses of the CDF family members revealed that the different orthologs are expressed in all fungal structures analyzed, except RiZnT1 that was expressed at very low levels in germinated spores (Table $\mathbf{1}$ ).

\section{THE NATURAL RESISTANCE-ASSOCIATED MACROPHAGE PROTEINS (NRAMP) FAMILY OF DIVALENT METAL TRANSPORTERS}

The NRAMP family constitutes a class of divalent metal transporters that are highly conserved from bacteria to mammals. These transporters use the transmembrane proton gradient to facilitate transport of a broad range of divalent cations toward the cytosol. S. cerevisiae has three homologs of this family in its genome, SMF1, SMF2, and SMF3. SMF1, and SMF2 mainly transport Mn, although SMF1 also transports Fe. While SMF1 operates at the plasma membrane in the uptake of either Mn or Fe (Chen et al., 1999; Portnoy et al., 2000), SMF2 is localized on membranes of intracellular Golgi vesicles, being involved in transport of Mn out of the vesicles (Reddi et al., 2009). SMF3 exports iron from the vacuole to the cytosol (Diffels et al., 2006), and together with CCC1, is responsible for Fe homeostasis in this organelle.
Searches in the R. irregularis genome led to the identification of four putative NRAMP homologs, all of them having the signature sequence DPGN. The sequences from Basidiomycota clearly separated from those of Ascomycota in the phylogenetic tree. The $R$. oryzae and $R$. irregularis homologs were grouped together in two different clades (Figure 8). Analysis of the available gene expression profiles of $R$. irregularis revealed that SMF1 and SMF3.1 are expressed in all fungal structures and that RiSMF1 and RiSMF2 are expressed at very low levels in germinated spores (Tisserant et al., 2012).

\section{CONCLUSION}

The present analysis aimed at establishing a repertoire of candidate genes that represent the genetic potential for transport of Fe, $\mathrm{Cu}$, and $\mathrm{Zn}$ in $R$. irregularis. We have revealed the presence of at least 30 genes encoding putative transition metal transporters, showing all of them detectable transcript levels in the fungal structures analyzed. Figure 9 summarizes the candidate genes identified

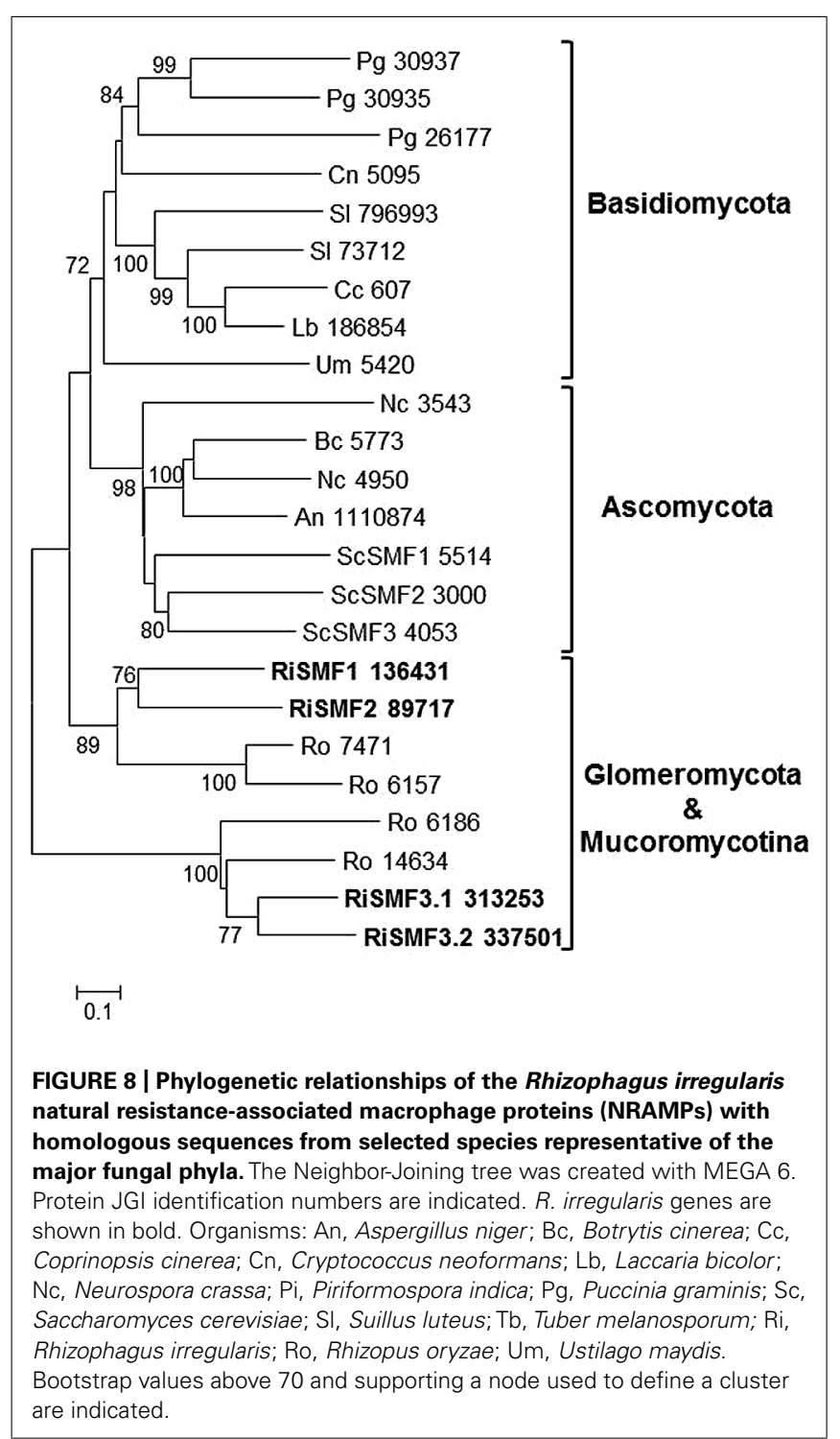




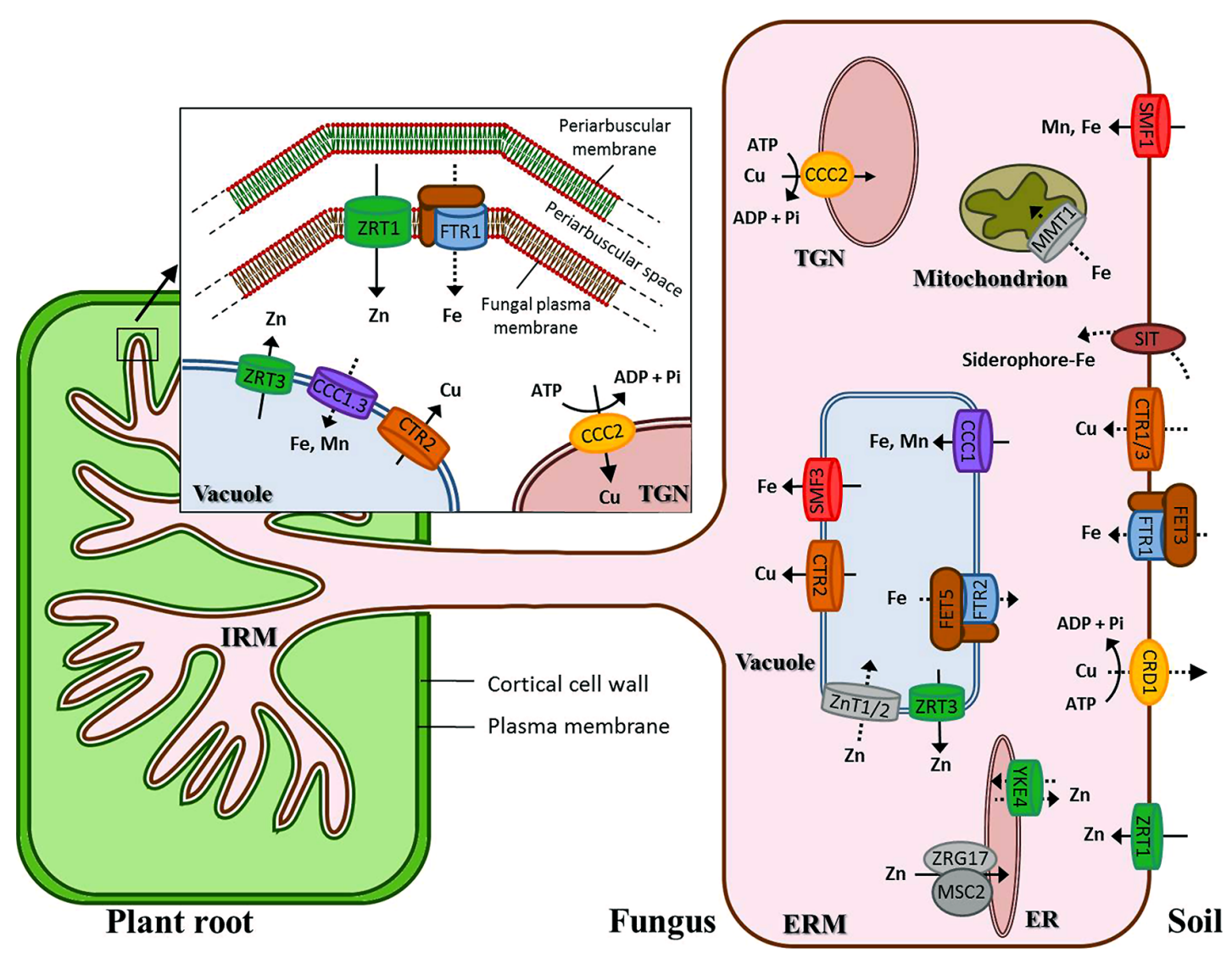

FIGURE 9 | Schematic representation of the putative $\mathrm{Cu}, \mathrm{Fe}$, and $\mathrm{Zn}$ transport systems in Rhizophagus irregularis. Transcripts for all these transporters have been detected in symbiotic roots and germinated spores. Discontinuous arrows refer to transporters whose transcript levels in the ERM have not been determined yet. Transcripts up-regulated by more than 2.5-fold in the symbiotic roots are shown in the intraradical mycelium (IRM), except ZnT1 that was expressed at very low levels in germinated spores and
SMF1 that was only up-regulated in the symbiotic roots relative to germinated spores but not to the ERM. Putative Cu transporters (CTR) are in dark orange; $\mathrm{P}_{1 \mathrm{~B}}$-or Cu-ATPases (CCC2) in light orange; the oxidase-dependent $\mathrm{Fe}^{2+}$ transporter (OFeT) family members in brown (ferroxidases) and blue (permeases); zinc-iron permeases (ZIPS) in green; cation diffusion facilitators (CDFs) in gray, NRAMPs in red and VITs in purple. $\mathrm{ER}$, endoplasmic reticulum; TGN, trans-Golgi network. in this genomic survey. The sequences and expression information reported herein will be useful for further investigation of the roles of these transport proteins in $\mathrm{Cu}, \mathrm{Fe}$, and $\mathrm{Zn}$ homeostasis in AMF and in the symbiosis. A comprehensive physiological analysis of the current dataset needs detailed characterization of the encoded proteins. However, we would like to highlight two features that stood out in this in silico analysis: (i) expansion of some families of metal transporters, specifically of Cu-ATPases, VITs, and NRAMPs, and (ii) up-regulation of a certain number of genes putatively encoding transport proteins mediating the influx of Fe/Zn (RiFTR1, RiZRT1) and the mobilization of the vacuolar $\mathrm{Cu} / \mathrm{Zn}$ stores (RiCTR2, RiZRT3) in the intraradical phase of the fungus. Since these transporters are unlikely to be involved in metal transfer to the plant, they should play a role in maintaining $\mathrm{Fe}, \mathrm{Cu}$, and $\mathrm{Zn}$ homeostasis in the IRM. Based on these observations we speculate that metal homeostasis in the places of close interactions between the plant and the fungus is needed for symbiotic development, as it has been shown in the mutualistic symbioses formed between Epichloë endophytes and the Poaceae. The challenge now is to functionally characterize these transporters and to identify their location and roles in the symbiosis.

\section{AUTHOR CONTRIBUTIONS}

The work presented here was carried out in collaboration between all authors. Elisabeth Tamayo and Tamara Gómez-Gallego performed the majority of the in silico analyses. Concepción AzcónAguilar and Nuria Ferrol defined the research theme. Nuria Ferrol coordinated the project and Elisabeth Tamayo and Nuria Ferrol wrote the manuscript. All authors have contributed to, seen and approved the manuscript.

\section{ACKNOWLEDGMENTS}

This research was supported by the Spanish Ministry of Economy and Competitivity (Project AGL2012-35611). Elisabeth Tamayo was supported by a Ph.D. contract (I3P) from the Spanish National Research Council (CSIC) and Tamara Gómez-Gallego by a Ph.D. contract from the Spanish Ministry of Economy and Competitivity. We are grateful to Ascensión Valderas for excellent technical assistance. 


\section{REFERENCES}

Askwith, C., and Kaplan, J. (1997). An oxidase-permease-based iron transport system in Schizosaccharomyces pombe and its expression in Saccharomyces cerevisiae. J. Biol. Chem. 272, 401-405. doi: 10.1074/jbc.272.1.401

Barhoom, S., Kupiec, M., Zhao, X., Xu, J.-R., and Sharon, A. (2008). Functional characterization of CgCTR2, a putative vacuole copper transporter that is involved in germination and pathogenicity in Colletotrichum gloeosporioides. Eukaryot. Cell 7, 1098-1108. doi: 10.1128/EC.00109-07

Blaudez, D., and Chalot, M. (2011). Characterization of the ER-located zinc transporter ZnT1 and identification of a vesicular zinc storage compartment in Hebeloma cylindrosporum. Fungal Genet. Biol. 48, 496-503. doi: 10.1016/j.fgb.2010.11.007

Chen, X.-Z., Peng, J.-B., Cohen, A., Nelson, H., Nelson, N., and Hediger, M. A. (1999). Yeast SMF1 mediates $\mathrm{H}^{+}$-coupled iron uptake with concomitant uncoupled cation currents. J. Biol. Chem. 274, 35089-35094. doi: 10.1074/jbc.274.49.35089

Cornejo, P., Pérez-Tienda, J., Meier, S., Valderas, A., Borie, F., Azcón-Aguilar, C., et al. (2013). Copper compartmentalization in spores as a survival strategy of arbuscular mycorrhizal fungi in Cu-polluted environments. Soil Biol. Biochem. 57, 925-928. doi: 10.1016/j.soilbio.2012.10.031

Dancis, A., Haile, D., Yuan, D. S., and Klausner, R. D. (1994). The Saccharomyces cerevisiae copper transport Protein (Ctr1p). J. Biol. Chem. 269, 25660-25667.

del Val, C., Barea, J. M., and Azcón-Aguilar, C. (1999). Diversity of arbuscular mycorrhizal fungus populations in heavy-metal-contaminated soils. Appl. Environ. Microbiol. 65, 718-723.

Diffels, J. F., Seret, M.-L., Goffeau, A., and Baret, P. V. (2006). Heavy metal transporters in Hemiascomycete yeasts. Biochimie 88, 1639-1649. doi: 10.1016/j.biochi.2006.08.008

Diss, L., Blaudez, D., Gelhaye, E., and Chalot, M. (2011). Genome-wide analysis of fungal manganese transporters, with an emphasis on Phanerochaete chrysosporium. Environ. Microbiol. Rep. 3, 367-382. doi: 10.1111/j.1758-2229.2010. 00235.x

Dix, D. R., Bridgham, J. T., Broderius, M. A., Byersdorfer, C. A., and Eide, D. J. (1994). The FET4 gene encodes the low affinity Fe(II) transport protein of Saccharomyces cerevisiae. J. Biol. Chem. 269, 26092-26099.

Eichhorn, H., Lessing, F., Winterberg, B., Schirawski, J., Kämper, J., Müller, P., et al. (2006). A ferroxidation/permeation iron uptake system is required for virulence in Ustilago maydis. Plant Cell 18, 3332-3345. doi: 10.1105/tpc.106.043588

Eide, D. J. (2006). Zinc transporters and the cellular trafficking of zinc. Biochim. Biophys. Acta 1763, 711-722. doi: 10.1016/j.bbamcr.2006.03.005

Fang, H.-M., and Wang, Y. (2002). Characterization of iron-binding motifs in Candida albicans high-affinity iron permease CaFtrlp by site-directed mutagenesis. Biochem. J. 368, 641-647. doi: 10.1042/BJ20021005

Ferrol, N., González-Guerrero, M., Valderas, A., Benabdellah, K., and Azcón-Aguilar, C. (2009). Survival strategies of arbuscular mycorrhizal fungi in Cu-polluted environments. Phytochem. Rev. 8, 551-559. doi: 10.1007/s11101-009-9133-9

Festa, R. A., and Thiele, D. J. (2011). Copper: an essential metal in biology. Curr. Biol. 21, 877-883. doi: 10.1016/j.cub.2011.09.040

Göhre, V., and Paszkowski, U. (2006). Contribution of the arbuscular mycorrhizal symbiosis to heavy metal phytoremediation. Planta 223, 1115-1122. doi: 10.1007/s00425-006-0225-0

González-Guerrero, M., Azcón-Aguilar, C., Mooney, M., Valderas, A., MacDiarmid, C. W., Eide, D. J., et al. (2005). Characterization of a Glomus intraradices gene encoding a putative $\mathrm{Zn}$ transporter of the cation diffusion facilitator family. Fungal Genet. Biol. 42, 130-140. doi: 10.1016/j.fgb.2004.10.007

González-Guerrero, M., Cano, C., Azcón-Aguilar, C., and Ferrol, N. (2007). GintMT1 encodes a functional metallothionein in Glomus intraradices that responds to oxidative stress. Mycorrhiza 17, 327-335. doi: 10.1007/s00572-0070108-7

González-Guerrero, M., Hong, D., and Argüello, J. M. (2009). Chaperone-mediated $\mathrm{Cu}^{+}$delivery to $\mathrm{Cu}^{+}$transport ATPases: requirement of nucleotide binding. $J$. Biol. Chem. 284, 20804-20811. doi: 10.1074/jbc.M109.016329

González-Guerrero, M., Melville, L. H., Ferrol, N., Lott, J. N. A., Azcón-Aguilar, C., and Peterson, R. L. (2008). Ultrastructural localization of heavy metals in the extraradical mycelium and spores of the arbuscular mycorrhizal fungus Glomus intraradices. Can. J. Microbiol. 54, 103-110. doi: 10.1139/w07-119

Greenshields, D. L., Liu, G., Feng, J., Selvaraj, G., and Wei, Y. (2007). The siderophore biosynthetic gene SID1, but not the ferroxidase gene FET3, is required for full Fusarium graminearum virulence. Mol. Plant Pathol. 8, 411-421. doi: 10.1111/j.1364-3703.2007.00401.x

Gsaller, F., Eisendle, M., Lechner, B. E., Schrettl, M., Lindner, H., Müller, D., et al. (2012). The interplay between vacuolar and siderophore-mediated iron storage in Aspergillus fumigatus. Metallomics 4, 1262-1270. doi: 10.1039/c2mt20179h

Haas, H., Eisendle, M., and Turgeon, B. G. (2008). Siderophores in fungal physiology and virulence. Annu. Rev. Phytopathol. 46, 149-187. doi: 10.1146/annurev.phyto.45.062806.094338

Haas, H., Schoeser, M., Lesuisse, E., Ernst, J. F., Parson, W., Abt, B., et al. (2003). Characterization of the Aspergillus nidulans transporters for the siderophores enterobactin and triacetylfusarinine C. Biochem. J. 371, 505-513. doi: 10.1042/BJ20021685

Han, K., Do, E., and Jung, W. H. (2012). A human fungal pathogen Cryptococcus neoformans expresses three distinct iron permease homologs. J. Microbiol. Biotechnol. 22, 1644-1652. doi: 10.4014/jmb.1209.09019

Haselwandter, K., Häninger, G., Ganzera, M., Haas, H., Nicholson, G., and Winkelmann, G. (2013). Linear fusigen as the major hydroxamate siderophore of the ectomycorrhizal Basidiomycota Laccaria laccata and Laccaria bicolor. Biometals 26, 969-979. doi: 10.1007/s10534-013-9673-8

Hassett, R., and Kosman, D. J. (1995). Evidence for Cu (II) reduction as a component of copper uptake by Saccharomyces cerevisiae. J. Biol. Chem. 270, 128-134. doi: 10.1074/jbc. 270.1 .128

Hogekamp, C., and Küster, H. (2013). A roadmap of cell-type specific gene expression during sequential stages of the arbuscular mycorrhiza symbiosis. BMC Genomics 14:306. doi: 10.1186/1471-2164-14-306

Howard, D. H. (1999). Acquisition, transport, and storage of iron by pathogenic fungi. Clin. Microbiol. Rev. 12, 394-404.

Johnson, L. J., Koulman, A., Christensen, M., Lane, G. A., Fraser, K., Forester, N., et al. (2013). An extracellular siderophore is required to maintain the mutualistic interaction of Epichloë festucae with Lolium perenne. PLoS Pathog. 9:e1003332. doi: 10.1371/journal.ppat.1003332

Khouja, H. R., Abbà, S., Lacercat-Didier, L., Daghino, S., Doillon, D., Richaud, P., et al. (2013). OmZnT1 and OmFET, two metal transporters from the metal-tolerant strain $\mathrm{Zn}$ of the ericoid mycorrhizal fungus Oidiodendron maius, confer zinc tolerance in yeast. Fungal Genet. Biol. 52, 53-64. doi: 10.1016/j.fgb.2012.11.004

Kim, B. E., Nevitt, T., and Thiele, D. J. (2008). Mechanisms for copper acquisition, distribution and regulation. Nat. Chem. Biol. 4, 176-185. doi: 10.1038/nchembio.72

Kosman, D. J. (2010). Redox cycling in iron uptake, efflux, and trafficking. J. Biol. Chem. 285, 26729-26735. doi: 10.1074/jbc.R110.113217

Kumánovics, A., Poruk, K. E., Osborn, K. A., Ward, D. M., and Kaplan, J. (2006). YKE4 (YIL023C) encodes a bidirectional zinc transporter in the endoplasmic reticulum of Saccharomyces cerevisiae. J. Biol. Chem. 281, 22566-22574. doi: 10.1074/jbc.M604730200

Kwok, E. Y., Severance, S., and Kosman, D. J. (2006). Evidence for iron channeling in the Fet3p-Ftrlp high-affinity iron uptake complex in the yeast plasma membrane. Biochemistry 45, 6317-6327. doi: 10.1021/bi052173c

Lesuisse, E., and Labbe, P. (1989). Reductive and non-reductive mechanisms of iron assimilation by the yeast Saccharomyces cerevisiae. J. Gen. Microbiol. 135, 257-263. doi: 10.1099/00221287-135-2-257

Li, L., Chen, O. S., McVey Ward, D., and Kaplan, J. (2001). CCC1 is a transporter that mediates vacuolar iron storage in yeast. J. Biol. Chem. 276, 29515-29519. doi: 10.1074/jbc.M103944200

Lin, K., Limpens, E., Zhang, Z., Ivanov, S., Saunders, D. G. O., Mu, D., et al. (2014). Single nucleus genome sequencing reveals high similarity among nuclei of an endomycorrhizal fungus. PLoS Genet. 10:e1004078. doi: 10.1371/journal.pgen.1004078

Lin, S., and Culotta, V. C. (1996). Suppression of oxidative damage by Saccharomyces cerevisiae ATX2, which encodes a manganese-trafficking protein that localizes to Golgi-like vesicles. Mol. Cell. Biol. 16, 6303-6312.

Lingua, G., Franchin, C., Todeschini, V., Castiglione, S., Biondi, S., Burlando, B., et al. (2008). Arbuscular mycorrhizal fungi differentially affect the response to high zinc concentrations of two registered poplar clones. Environ. Pollut. 153, 137-147. doi: 10.1016/j.envpol.2007.07.012

MacDiarmid, C. W., Milanick, M. A., and Eide, D. J. (2002). Biochemical properties of vacuolar zinc transport systems of Saccharomyces cerevisiae. J. Biol. Chem. 277, 39187-39194. doi: 10.1074/jbc.M205052200 
Marjorette, M., Peña, O., Puig, S., and Thiele, D. J. (2000). Characterization of the Saccharomyces cerevisiae high affinity copper transporter Ctr3. J. Biol. Chem. 275, 33244-33251. doi: 10.1074/jbc.M005392200

Mei, B., Budde, A. D., and Leong, S. A. (1993). sid1, a gene initiating siderophore biosynthesis in Ustilago maydis: molecular characterization, regulation by iron, and role in phytopathogenicity. Proc. Natl. Acad. Sci. U.S.A. 90, 903-907. doi: 10.1073/pnas.90.3.903

Montanini, B., Blaudez, D., Jeandroz, S., Sanders, D., and Chalot, M. (2007). Phylogenetic and functional analysis of the Cation Diffusion Facilitator (CDF) family: improved signature and prediction of substrate specificity. BMC Genomics 8:107. doi: 10.1186/1471-2164-8-107

Nayuki, K., Chen, B., Ohtomo, R., and Kuga, Y. (2014). Cellular imaging of cadmium in resin sections of arbuscular mycorrhizas using synchrotron micro X-ray fluorescence. Microbes Environ. 29, 60-66. doi: 10.1264/jsme2.ME13093

Nies, D. H. (2007). How cells control zinc homeostasis. Science 292, 2488-2492. doi: 10.1126/science.1149048

Nishida, S., Mizuno, T., and Obata, H. (2008). Involvement of histidine-rich domain of ZIP family transporter TjZNT1 in metal ion specificity. Plant Physiol. Biochem. 46, 601-606. doi: 10.1016/j.plaphy.2008.02.011

Parisot, D., Dufresne, M., Veneault, C., Laugé, R., and Langin, T. (2002). clap1, a gene encoding a copper-transporting ATPase involved in the process of infection by the phytopathogenic fungus Colletotrichum lindemuthianum. Mol. Genet. Genomics 268, 139-151. doi: 10.1007/s00438-002-0744-8

Park, Y.-S., Choi, I.-D., Kang, C.-M., Ham, M.-S., Kim, J.-H., Kim, T.-H., et al. (2006). Functional identification of high-affinity iron permeases from Fusarium graminearum. Fungal Genet. Biol. 43, 273-282. doi: 10.1016/j.fgb.2005.12.005

Philpott, C. C., and Protchenko, O. (2008). Response to iron deprivation in Saccharomyces cerevisiae. Eukaryot. Cell 7, 20-27. doi: 10.1128/EC.00354-07

Plattner, H. J., and Diekmann, H. (1994). "Enzymology of siderophore biosynthesis," in Metal Ions in Fungi, eds G. Winkelmann and D. R. Winge (New York, NY: M. Dekker, Inc.), 99-116.

Portnoy, M. E., Liu, X. F., and Culotta, V. C. (2000). Saccharomyces cerevisiae expresses three functionally distinct homologues of the nramp family of metal transporters. Mol. Cell. Biol. 20, 7893-7902. doi: 10.1128/MCB.20.21.78937902.2000

Portnoy, M. E., Schmidt, P. J., Rogers, R. S., and Culotta, V. C. (2001). Metal transporters that contribute copper to metallochaperones in Saccharomyces cerevisiae. Mol. Genet. Genomics 265, 873-882. doi: 10.1007/s004380100482

Puig, S., and Thiele, D. J. (2002). Molecular mechanisms of copper uptake and distribution. Curr. Opin. Chem. Biol. 6, 171-180. doi: 10.1016/S1367-5931(02) 00298-3

Reddi, A. R., Jensen, L. T., Naranuntarat, A., Rosenfeld, L., Leung, E., Shah, R., etal. (2009). The overlapping roles of manganese and $\mathrm{Cu} / \mathrm{Zn}$ SOD in oxidative stress protection. Free Radic. Biol. Med. 46, 154-162. doi: 10.1016/j.freeradbiomed.2008.09.032

Roman, D. G., Dancis, A., Anderson, G. J., and Klausner, R. D. (1993). The fission yeast ferric reductase gene $f r p 1^{+}$is required for ferric iron uptake and encodes a protein that is homologous to the gp91-phox subunit of the human NADPH phagocyte oxidoreductase. Mol. Cell. Biol. 13, 4342-4350. doi: 10.1128/MCB.13.7.4342

Saha, R., Saha, N., Donofrio, R. S., and Bestervelt, L. L. (2013). Microbial siderophores: a mini review. J. Basic Microbiol. 53, 303-317. doi: 10.1002/jobm.201100552

Saitoh, Y., Izumitsu, K., Morita, A., and Tanaka, C. (2010). A copper-transporting ATPase BcCCC2 is necessary for pathogenicity of Botrytis cinerea. Mol. Genet. Genomics 284, 33-43. doi: 10.1007/s00438-010-0545-4

Saitoh, Y., Izumitsu, K., and Tanaka, C. (2009). Phylogenetic analysis of heavy-metal ATPases in fungi and characterization of the copper-transporting ATPase of Cochliobolus heterostrophus. Mycol. Res. 113, 737-745. doi: 10.1016/j.mycres.2009.02.009

Schaible, U. E., and Kaufmann, S. H. (2004). Iron and microbial infection. Nat. Rev. Microbiol. 2, 946-953. doi: 10.1038/nrmicro1046

Schrettl, M., Winkelmann, G., and Haas, H. (2004). Ferrichrome in Schizosaccharomyces pombe- an iron transport and iron storage compound. Biometals 17, 647-654. doi: 10.1007/s10534-004-1230-z
Schwecke, T., Göttling, K., Durek, P., Dueñas, I., Käufer, N. F., Zock-Emmenthal, S., et al. (2006). Nonribosomal peptide synthesis in Schizosaccharomyces pombe and the architectures of ferrichrome-type siderophore synthetases in fungi. Chembiochem 7, 612-622. doi: 10.1002/cbic.200500301

Schwyn, B., and Neilands, J. B. (1987). Universal chemical assay for the detection and determination of siderophores. Anal. Biochem. 160, 47-56. doi: 10.1016/00032697(87)90612-9

Simm, C., Lahner, B., Salt, D., LeFurgey, A., Ingram, P., Yandell, B., et al. (2007). Saccharomyces cerevisiae vacuole in zinc storage and intracellular zinc distribution. Eukaryot. Cell 6, 1166-1177. doi: 10.1128/EC.00077-07

Smith, S. E., and Read, D. J. (2008). Mycorrhizal Symbiosis. London: Academic Press Spizzo, T., Byersdorfer, C., Duesterhoeft, S., and Eide, D. (1997). The yeast FET5 gene encodes a FET3-related multicopper oxidase implicated in iron transport. Mol. Gen. Genet. 256, 547-556. doi: 10.1007/PL00008615

Tisserant, E., Kohler, A., Dozolme-Seddas, P., Balestrini, R., Benabdellah, K., Colard, A., et al. (2012). The transcriptome of the arbuscular mycorrhizal fungus Glomus intraradices (DAOM 197198) reveals functional tradeoffs in an obligate symbiont. New Phytol. 193, 755-769. doi: 10.1111/j.1469-8137.2011.03948.x

Tisserant, E., Malbreil, M., Kuo, A., Kohler, A., Symeonidi, A., Balestrini, R., et al. (2013). Genome of an arbuscular mycorrhizal fungus provides insight into the oldest plant symbiosis. Proc. Natl. Acad. Sci. U.S.A. 110, 20117-20122. doi: 10.1073/pnas.1313452110

Turnau, K., Kottke, I., and Oberwinkler, F. (1993). Element localization in mycorrhizal roots of Pteridium aquilinum (L.) Kuhn collected from experimental plots treated with cadmium dust. New Phytol. 123, 313-324. doi: 10.1111/j.1469-8137.1993.tb03741.x

Urbanowski, J. L., and Piper, R. C. (1999). The iron transporter Fthlp forms a complex with the Fet5 iron oxidase and resides on the vacuolar membrane. J. Biol. Chem. 274, 38061-38070. doi: 10.1074/jbc.274.53.38061

Valko, M., Morris, H., and Cronin, M. T. (2005). Metals, toxicity and oxidative stress. Curr. Med. Chem. 12, 1161-1208. doi: 10.2174/0929867053764635

van Ho, A., Ward, D. M., and Kaplan, J. (2002). Transition metal transport in yeast. Annu. Rev. Microbiol. 56, 237-261. doi: 10.1146/annurev.micro.56. 012302.160847

Weissman, Z., Berdicevsky, I., Cavari, B. Z., and Kornitzer, D. (2000). The high copper tolerance of Candida albicans is mediated by a P-type ATPase. Proc. Natl. Acad. Sci.U.S.A. 97, 3520-3525. doi: 10.1073/pnas.97.7.3520

Yuan, D. S., Stearman, R., Dancis, A., Dunn, T., Beeler, T., and Klausner, R. D. (1995). The Menkes/Wilson disease gene homologue in yeast provides copper to a ceruloplasmin-like oxidase required for iron uptake. Proc. Natl. Acad. Sci. U.S.A. 92, 2632-2636. doi: 10.1073/pnas.92.7.2632

Yuan, M., Li, X., Xiao, J., and Wang, S. (2011). Molecular and functional analyses of COPT/Ctr-type copper transporter-like gene family in rice. BMC Plant Biol. 11:69. doi: 10.1186/1471-2229-11-69

Zhao, H., and Eide, D. (1996). The ZRT2 gene encodes the low affinity zinc transporter in Saccharomyces cerevisiae. J. Biol. Chem. 271, 23203-23210. doi: 10.1074/jbc.271.38.23203

Conflict of Interest Statement: All authors declare that the research was conducted in the absence of any commercial or financial relationships that could be construed as a potential conflict of interest.

Received: 11 August 2014; accepted: 24 September 2014; published online: 14 October 2014.

Citation: Tamayo E, Gómez-Gallego T, Azcón-Aguilar C and Ferrol N (2014) Genomewide analysis of copper, iron and zinc transporters in the arbuscular mycorrhizal fungus Rhizophagus irregularis. Front. Plant Sci. 5:547. doi: 10.3389/fpls.2014.00547

This article was submitted to Plant Traffic and Transport, a section of the journal Frontiers in Plant Science.

Copyright (c) 2014 Tamayo, Gómez-Gallego, Azcón-Aguilar and Ferrol. This is an openaccess article distributed under the terms of the Creative Commons Attribution License (CC BY). The use, distribution or reproduction in other forums is permitted, provided the original author(s) or licensor are credited and that the original publication in this journal is cited, in accordance with accepted academic practice. No use, distribution or reproduction is permitted which does not comply with these terms. 